\title{
A Mathematical Model for Selecting Third-Party Reverse Logistics Providers
}

\author{
Reza Farzipoor Saen \\ Department of Industrial Management, Faculty of Management and Accounting, Islamic Azad \\ University - Karaj Branch, Karaj, Iran, P. O. Box: 31485-313 \\ Tel: 0098 (261) 4418144-6 \\ Fax: 0098 (261) 4418156 \\ E-mail: farzipour@yahoo.com
}

\begin{abstract}
Generally, many optimization models of third-party reverse logistics (3PL) provider selection assume that cardinal data, with less emphasis on ordinal data, exist. However, to select the best 3PL providers, this assumption is not realistic because ordinal data are vital. For dealing with this difficulty and selecting the most efficient 3PL provider in the conditions that both ordinal and cardinal data are present, a methodology is introduced, which is based on imprecise data envelopment analysis (IDEA). A numerical example demonstrates the application of the proposed method.
\end{abstract}

Keywords: Third-party reverse logistics provider, Data envelopment analysis, Cardinal and ordinal data

\section{Introduction}

Logistics plays a significant role in integrating the supply chain of industries. However, as the market becomes more global, logistics is now seen as an important area where industries can cut costs and improve their customer service quality. Logistics outsourcing is an emerging trend in the global market. Basically, a third-party reverse logistics (3PL) provider involves using external companies to perform logistics functions which have been conventionally operational within an organization. The main benefits of 
logistics alliances are to allow the outsourcing company to concentrate on the core competence, increase the efficiency, improve the service, reduce the transportation cost, restructure the supply chains, and establish the marketplace legitimacy. Hence, a proper 3PL provider which meets various demands is crucial for the growth and competence of an enterprise (Liu and Wang (in press)).

On the other hand, many manufacturers have understood that their core competences are not in the logistics-field, and have therefore progressively sought to buy logistics services and functions from 3PL provider (Bottani and Rizzi, (2006)).

Reuse of products and materials is not a new phenomenon. Metal scrap brokers, waste paper recycling, and deposit systems for softdrink bottles are all examples that have been around for a long time. In these cases recovery of the used products is economically more attractive than disposal. In the recent years, the growth of environmental concerns has given "reuse" increasing attention. Waste reduction efforts have promoted the idea of material cycles instead of a "one way" economy. The reuse opportunities give rise to a new material flow from the user back to the sphere of producers. The management of this material flow opposite to the conventional supply chain flow is the concern of the recently emerged field of "reverse logistics".

Reverse logistics encompasses the logistics activities all the way from used products no longer required by the user to products again usable in a market. The typical reverse logistics operations include the activities a firm, which uses returned merchandise due to product recalls, excess inventory, salvage, unwanted or outdated products, etc. In addition, it includes the recycling programs, hazardous material programs, and disposition of obsolete equipment and asset recovery.

The importance of studying reverse logistics has increased in recent years for several reasons (Prahinski and Kocabasoglu (2006)):

- The amount of product returns can be very high, with some industries experiencing returns at over $50 \%$ of sales.

- Sales opportunities in secondary and global markets have increased revenue generation from previously discarded products. 
- End-of-life take-back laws have proliferated over the past decade in the developed countries, requiring businesses to effectively manage the entire life of the product.

- Consumers have successfully pressured businesses to take responsibility for the disposal of their products that contain hazardous waste.

- Landfill capacity has become limited and expensive. Alternatives such as repackaging, remanufacturing and recycling have become more prevalent and viable.

With regard to the above issues and additional pressures from evolving environmental and electronic commerce practice points to strategic implications of reverse logistics decisions, one of which is the outsource decision, which may include the selection of 3PL providers. In summary, there are numerous reasons for selecting a 3PL provider. Once the decision has been made to work with a 3PL provider the next decision is to determine which provider. Selecting reverse logistics providers from a large number of possible 3PL providers with varying levels of capabilities and potential is a complicated and a time-consuming task requiring multiple criteria decision making solution approaches.

This paper proposes a method for selecting the best 3PL providers in the presence of both cardinal and ordinal data. The objective of this paper is to propose a method for selecting 3PL providers in the conditions that both ordinal and cardinal data are present (without relying on weight assignment by decision makers). The approach presented in this paper has some distinctive features.

- The proposed model considers cardinal and ordinal data for 3PL provider selection.

- The proposed model deals with imprecise data in a direct manner.

- 3PL provider selection is a straightforward process carried out by the proposed model.

- The proposed model does not demand weights from the decision maker.

This paper proceeds as follows. In Section 2, literature review is presented. In Section 3 , the method that selects the 3PL providers is introduced. Numerical example and 
managerial implications are discussed in Sections 4 and 5, respectively. Section 6 discusses concluding remarks.

\section{Literature review}

Some mathematical programming approaches have been used for 3PL provider selection in the past. Meade and Sarkis (2002) applied analytic network process (ANP) for 3PL provider selection. Göl and Çatay (2007) used analytic hierarchy process (AHP) for selecting 3PL providers. They highlighted the efforts of a leading Turkish automotive company to restructure its supply chain for export parts. To select the best 3PL providers in the presence of vagueness, Efendigil et al. (2008) developed a two-phase model based on artificial neural networks and fuzzy AHP.

However, AHP and ANP have two main weaknesses. First subjectivity of AHP and ANP is a weakness. The decision maker provides the values for the pairwise comparisons and, therefore, the model is very dependent on the weightings provided by the decision maker. Second the time necessary for completion of such a model is a weakness. The number of pairwise comparisons required could become cumbersome. Meanwhile, when the number of alternatives and criteria grows, the pairwise comparison process becomes difficult, and the risk of generating inconsistencies grows, hence jeopardizing the practical applicability of AHP and ANP.

Bottani and Rizzi (2006) presented a multi-attribute approach for the selection and ranking of the most suitable 3PL provider. Their approach is based on the TOPSIS (Technique for Order Preference by Similarity to Ideal Solution) technique and the fuzzy set theory. To select 3PL providers, Cao et al. (2007) proposed a two-stage method based on the social welfare function and TOPSIS. In the first stage, they used the social welfare function theory for selection potential providers from too many 3PLs. Then, TOPSIS theory was used for final selection, avoiding the subjective estimation of experts.

Işıklar et al. (2007) presented an intelligent decision support framework for 3PL selection. The proposed framework integrates case-based reasoning, rule-based reasoning and compromise programming techniques in fuzzy environment. Liu and Wang (in press) developed an integrated fuzzy approach for selection of 3PL providers. Their method consists of three different techniques: (1) use fuzzy Delphi method to identify important 
evaluation criteria; (2) apply fuzzy inference method to eliminate unsuitable 3PL providers; and, (3) develop a fuzzy linear assignment approach for the final selection. Qureshi et al. (2008) described TOPSIS for selecting potential 3PL providers in fuzzy environment. Various selection criteria measured in linguistics term in vague and subjective reference were accounted using triangular fuzzy numbers. The case problem demonstrated fuzzy multi-criteria decision making method to evaluate the potential 3PL providers by assigning weight to each criterion and later on synthesizing the capability exhibited by them.

However, as noted before, all of the abovementioned references suffer from subjective judgments. A technique that can deal with both ordinal and cardinal data and not relying on weight assignment by decision makers is needed to better model such situation.

Recently, Haas et al. (2003) applied data envelopment analysis (DEA) for selecting reverse logistics channels. However, they deal with cardinal data and do not consider ordinal data.

To the best of author's knowledge, in the DEA context, there is not any reference that deals with 3PL provider selection in the conditions that both ordinal and cardinal data are present.

\section{Proposed method for 3PL providers selection}

DEA proposed by Charnes et al. (1978) (Charnes, Cooper, Rhodes (CCR) model) and developed by Banker et al. (1984) (Banker, Charnes, Cooper (BCC) model) is an approach for evaluating the efficiencies of decision making units (DMUs). This evaluation is generally assumed to be based on a set of cardinal (quantitative) output and input factors. In many real world applications (especially 3PL provider selection problems), however, it is essential to take into account the existence of ordinal (qualitative) factors when rendering a decision on the performance of a DMU. Very often, it is the case that for a factor such as 3PL provider reputation, one can, at most, provide a ranking of the DMUs from best to worst relative to this attribute. The capability of providing a more precise, quantitative measure reflecting such a factor is generally beyond the realm of reality. In some situations, such factors can be legitimately 
quantified, but very often; such quantification may be superficially forced as a modeling convenience. In situations such as that described, the data for certain influence factors (inputs and outputs) might better be represented as rank positions in an ordinal, rather than numerical sense. Refer again to the 3PL provider reputation example. In certain circumstances, the information available may permit one to provide a complete rank ordering of the DMUs on such a factor. Therefore, the data may be imprecise. To deal with imprecise data in DEA, imprecise data envelopment analysis (IDEA) models and methods have been developed. Imprecise data implies that some data are known only to the extent that the true values lie within prescribed bounds while other data are known only in terms of ordinal relations. When imprecision is taken into consideration, the associated DEA model becomes nonlinear, which makes its solution procedure difficult.

Suppose there is a set of $n$ peer DMUs, $\left\{\mathrm{DMU}_{j}: j=1,2, \ldots, n\right\}$, which produce multiple outputs $y_{r j}(r=1,2, \ldots, s)$, by utilizing multiple inputs $x_{i j}(i=1,2, \ldots, m)$. When a $\mathrm{DMU}_{o}$ is under evaluation by the CCR model, there is:

$\max \pi_{o}=\sum_{r=1}^{s} \mu_{r} y_{r o}$

s.t.

$$
\begin{aligned}
& \sum_{r=1}^{s} \mu_{r} y_{r j}-\sum_{i=1}^{m} w_{i} x_{i j} \leq 0 \quad \forall j, \\
& \sum_{i=1}^{m} w_{i} x_{i o}=1, \\
& \mu_{r}, w_{i} \geq 0 \quad \forall r, i .
\end{aligned}
$$

where $\mu_{r}$ is weight of the rth output and $w_{i}$ is weight of the ith input.

Cooper et al. (1999) and Kim et al. (1999) discussed that some of the outputs and inputs are imprecise data in the forms of bounded data, ordinal data, and ratio bounded data as follows.

\section{Bounded data}

$\underline{y}_{r j} \leq y_{r j} \leq \bar{y}_{r j}$ and $\underline{x}_{i j} \leq x_{i j} \leq \bar{x}_{i j}$ for $r \in B O, \quad i \in B I$, 
where $\underline{y}_{r j}$ and $\underline{x}_{i j}$ are the lower bounds and $\bar{y}_{r j}$ and $\bar{x}_{i j}$ are the upper bounds, and BO and BI represent the associated sets containing bounded outputs and bounded inputs, respectively.

Weak ordinal data

$y_{r j} \leq y_{r k}$ and $x_{i j} \leq x_{i k}$ for $j \neq k, \quad r \in D O, \quad i \in D I$,

or, to simplify the presentation,

$y_{r 1} \leq y_{r 2} \leq \cdots \leq y_{r k} \leq \cdots \leq y_{r n} \quad(r \in D O)$,

$x_{i 1} \leq x_{i 2} \leq \cdots \leq x_{i k} \leq \cdots \leq x_{i n} \quad(i \in D I)$,

where DO and DI represent the associated sets containing weak ordinal outputs and inputs, respectively.

Strong ordinal data

$y_{r 1}<y_{r 2}<\ldots<y_{r k}<\ldots<y_{r n} \quad(r \in \mathrm{SO})$,

$x_{i 1}<x_{i 2}<\ldots<x_{i k}<\ldots<x_{i n} \quad(i \in \mathrm{SI})$,

where SO and SI represent the associated sets containing strong ordinal outputs and inputs, respectively.

Ratio bounded data

$$
\begin{array}{ll}
L_{r j} \leq \frac{y_{r j}}{y_{r j_{o}}} \leq U_{r j} \quad\left(j \neq j_{o}\right) \quad(r \in R O), \\
G_{i j} \leq \frac{x_{i j}}{x_{i j_{o}}} \leq H_{i j} \quad\left(j \neq j_{o}\right) & (i \in R I),
\end{array}
$$

where $L_{r j}$ and $G_{i j}$ represent the lower bounds, and $U_{r j}$ and $H_{i j}$ represent the upper bounds. $\mathrm{RO}$ and RI represent the associated sets containing ratio bounded outputs and inputs, respectively.

If (2)-(8) are incorporated into model (1), there will be: 
$\max \pi_{o}=\sum_{r=1}^{s} \mu_{r} y_{r o}$

s.t.

$$
\begin{aligned}
& \sum_{r=1}^{s} \mu_{r} y_{r j}-\sum_{i=1}^{m} w_{i} x_{i j} \leq 0, \quad j=1, \cdots, n \\
& \sum_{i=1}^{m} w_{i} x_{i o}=1 \\
& \left(x_{i j}\right) \in \Theta_{i}^{-} \\
& \left(y_{r j}\right) \in \Theta_{r}^{+}, \\
& \mu_{r}, w_{i} \geq 0
\end{aligned}
$$

where $\left(x_{i j}\right) \in \Theta_{i}^{-}$and $\left(y_{r j}\right) \in \Theta_{r}^{+}$represent any or all of (2)-(8).

Obviously, model (9) is nonlinear and non-convex, because some of the outputs and inputs become unknown decision variables. Since model (9) is nonlinear and non-convex, consequently local optimum is produced and we cannot be sure whether this is the global optimum or not ${ }^{1}$.

To convert model (9) into the linear program, Zhu (2003) developed a simple approach by defining

$$
\begin{array}{ll}
X_{i j}=w_{i} x_{i j} & \forall i, j, \\
Y_{r j}=\mu_{r} y_{r j} & \forall r, j .
\end{array}
$$

Then model (9) can be converted into the following linear program:

$$
\pi_{o}^{*}=\max \quad \sum_{r=1}^{s} Y_{r o}
$$

s.t.

$$
\begin{aligned}
& \sum_{r=1}^{s} Y_{r j}-\sum_{i=1}^{m} X_{i j} \leq 0, \quad j=1, \cdots, n \\
& \sum_{i=1}^{m} X_{i o}=1, \\
& X_{i j} \in \tilde{D}_{i}^{-}, \\
& Y_{r j} \in \tilde{D}_{r}^{+}, \quad \\
& X_{i j} \geq 0 \quad \forall i, \\
& Y_{r j} \geq 0 \quad \forall r,
\end{aligned}
$$

where $\Theta_{r}^{+}$and $\Theta_{i}^{-}$are transformed into $\tilde{D}_{r}^{+}$and $\tilde{D}_{i}^{-}$with: 
1. bounded data: $\underline{y}_{r j} \mu_{r} \leq Y_{r j} \leq \mu_{r} \bar{y}_{r j}, \quad w_{i} \underline{X}_{i j} \leq X_{i j} \leq w_{i} \bar{x}_{i j}$;

2. ordinal data: $Y_{r j} \leq Y_{r k}$ and $X_{i j} \leq X_{i k} \forall j \neq k$ for some $r, i$;

3. ratio bounded data: $L_{r j} \leq \frac{Y_{r j}}{Y_{r j_{o}}} \leq U_{r j}$ and $G_{i j} \leq \frac{X_{i j}}{X_{i j_{o}}} \leq H_{i j} \quad\left(j \neq j_{o}\right)$;

4. cardinal data: $Y_{r j}=\hat{y}_{r j} \mu_{r}$ and $X_{i j}=w_{i} \hat{x}_{i j}$, where $\hat{y}_{r j}$ and $\hat{x}_{i j}$ represent cardinal data.

In the next section, a numerical example is presented.

\section{Numerical example}

The data set for this example is partially taken from Farzipoor Saen (2007) and contains specifications on eighteen 3PL providers. The cardinal input considered is total cost of shipments (TC). 3PL provider reputation (3R) is included as a qualitative input while number of bills received from the 3PL provider without errors (NB) will serve as the bounded data output. 3R is an intangible factor that is not usually explicitly included in evaluation model for 3PL provider. This qualitative variable is measured on an ordinal scale. Table 1 depicts the 3PL provider's attributes.

Now the transformation process involved in model (11), is illustrated. That is, $\Theta_{1}^{-}=\left\{x_{11}=253 ; x_{12}=268 ; x_{13}=259 ; \ldots ; x_{118}=216\right\} \quad$ (cardinal data) $\Theta_{2}^{-}=\left\{x_{218} \geq x_{216} \geq \cdots \geq x_{217}\right\} \quad$ (ordinal data) $\Theta_{1}^{+}=\left\{50 \leq y_{11} \leq 65 ; 60 \leq y_{12} \leq 70 ; \quad 40 \leq y_{13} \leq 50 ; \ldots ; 90 \leq y_{118} \leq 150\right\}$ (bounded data)

By using (10), $\Theta_{1}^{-}, \Theta_{2}^{-}$, and $\Theta_{1}^{+}$are, respectively, transformed into

$$
\begin{aligned}
& \tilde{D}_{1}^{-}=\left\{X_{11}=253 w_{1} ; \quad X_{12}=268 w_{1} ; \quad X_{13}=259 w_{1} ; \cdots ; X_{118}=216 w_{1}\right\} \\
& \tilde{D}_{2}^{-}=\left\{X_{218} \geq X_{216} \geq \cdots \geq X_{217}\right\} \\
& \tilde{D}_{1}^{+}=\left\{50 \mu_{1} \leq Y_{11} \leq 65 \mu_{1} ; 60 \mu_{1} \leq Y_{12} \leq 70 \mu_{1} ; 40 \mu_{1} \leq Y_{13} \leq 50 \mu_{1} ; \cdots ; 90 \mu_{1} \leq Y_{118} \leq 150 \mu_{1}\right\}
\end{aligned}
$$

Applying model (11), the efficiency scores of 3PL providers (DMUs) have been presented in the last column of Table 1. 
Model (11) identified 3PL providers 4, 6, 8, 9, 11, 14, and 17 to be efficient with a relative efficiency score of 1 . The remaining eleven 3PL providers with relative efficiency scores of less than 1 are considered inefficient. Therefore, decision maker can choose one or more of these efficient 3PL providers which suit the logistics outsourcing needs of his/her company.

During the 3PL provider selection process, several points should be mentioned and discussed. First of all, the proposed method does not require subjective judgments of the decision makers in the evaluation process. Secondly, the inputs and outputs selected in this paper are not exhaustive by any means, but are some general measures that can be utilized to evaluate 3PL providers. In an actual application of this methodology, decision makers must carefully identify appropriate inputs and outputs measures to be used in the decision making process. Thirdly, during the entire selection process, large amount of information were directly offered by the individual 3PL provider. The decision makers may use the offered information to evaluate the performance of each 3PL provider. If the decision makers cannot exactly distinguish what the 3PL providers have done with what they plan to do, the misjudgment or bias towards a particular 3PL provider could be occurred. To avoid this situation, multiple on-site visits or gathering of relevant information indirectly are the feasible ways to obtain more accurate decision results. Finally, it should be noted that the relevant evaluation results are valid only for this example with its own decision environment and should not be generalized for other companies. In addition, the application of the proposed method may require significant time and efforts from the decision makers. Nevertheless, it is still worthwhile that the outsourcing company can reduce costs, focus on core competence, and most importantly, reduce the risk of selecting an inappropriate 3PL provider.

\section{Managerial implications}

Over the past few decades, increased competition caused by globalization and rapid technological advances has motivated firms to improve efficiency in supply chain management. Increasing efficiency in reverse logistics operations such as the recovery of the returned products is one way in which businesses attempted to maintain and increase competitiveness in the global economy. 
Many businesses prefer allocating their resources to core competency areas and choose to outsource their partial or overall logistics processes to 3PL providers. Utilizing 3PL providers in a closed-loop supply chain is also effective in ensuring sustainability since efficient reverse logistics services enable businesses with the opportunity to increase their profit margins, to differentiate their services from those of the competitors, to attract new clients to these services, and to enhance their status in the global supply chain network. On the other hand, if returns are not handled effectively, that is, when returned assets are not processed quickly or completely, considerable value may be lost. Hence, it is important to select an efficient 3PL provider to partner with the organization in the reverse logistics process.

Mathematical models provide important information that can be used by managers in making strategic or operational decisions. Managers can gain information about those 3PL providers that exhibit best practice so that they may gain from the experience of the more efficient, and this can lead to benefits derived from collaboration among the 3PL providers. Furthermore, the process of defining efficiency for a particular type of operation through the selection of the important inputs and outputs has significant strategic value.

\section{Concluding remarks}

Motivated by the growing significance of reverse logistics activities in an increasingly competitive global market, this study proposed a method for selecting appropriate and desirable 3PL providers. To select the most efficient 3PL provider in the conditions that both ordinal and cardinal factors are present, a methodology was introduced.

The results of this paper can be applied from both a manufacturer's and 3PL provider's perspective. The manufacturer can use it as a tool in selecting the "best" 3PL provider. The 3PL provider can use these results from a marketing perspective. A specific 3PL provider, who achieves a high mean score, when compared to the other 3PL

providers, can use these results for promoting its service. On the other hand, if a particular 3PL provider is poorly performing, then the 3PL provider can use the analysis 
for benchmarking purposes. This result may mean that the 3PL provider must provide better performance levels at the same input.

The problem considered in this study is at initial stage of investigation and much further researches can be done based on the results of this paper. Some of them are as follows:

Similar research can be repeated for dealing with ordinal data and bounded data by fuzzy sets. The other research can be accomplished for 3PL providers ranking in the presence of qualitative data, imprecise data, and stochastic data. Other potential extension to the methodology includes the case that some of the 3PL providers are slightly nonhomogeneous. One of the assumptions of all the classical models of DEA is based on complete homogeneity of DMUs (3PL providers), whereas this assumption in many real applications cannot be generalized. In other words, some inputs and/or outputs are not common for all the DMUs occasionally. Therefore, there is a need to a model that deals with these conditions. To compare the results of performance of proposed method with fuzzy DEA will be another research topic.

\section{Acknowledgement}

The author wishes to thank an anonymous reviewer for valuable suggestions and comments.

\section{References}

Banker R. D., Charnes A. and Cooper W. W. (1984) 'Some Methods for Estimating Technical and Scale Inefficiencies in Data Envelopment Analysis', Management Science, Vol. 30, No. 9, pp. 1078-1092.

Bottani E. and Rizzi A. (2006) 'A Fuzzy TOPSIS Methodology to Support Outsourcing of Logistics Services', Supply Chain Management: An International Journal, Vol. 11, No. 4, pp. 294-308.

Cao J., Wang W. W. and Cao G. (2007) 'Integration of the Social Welfare Function and TOPSIS Algorithm for 3PL Selection', Fourth International Conference on Fuzzy 
Systems and Knowledge Discovery (FSKD 2007), IEEE Computer Society, Vol. 3, pp. 596-600.

Charnes A., Cooper W. W. and Rhodes E. (1978) 'Measuring the Efficiency of Decision Making Units', European Journal of Operational Research, Vol. 2, No. 6, pp. 429-444.

Cooper W. W., Park K.S. and Yu G. (1999) 'IDEA and AR-IDEA: Models for Dealing with Imprecise Data in DEA', Management Science, Vol. 45, No. 4, pp. 597-607.

Efendigil T., Önüt S. and Kongar E. (2008) 'A Holistic Approach for Selecting a ThirdParty Reverse Logistics Provider in the Presence of Vagueness', Computers \& Industrial Engineering, Vol. 54, No. 2, pp. 269-287.

Farzipoor Saen R. (2007) 'Suppliers selection in the presence of both cardinal and ordinal data', European Journal of Operational Research, Vol. 183, No. 2, pp. 741-747.

Göl H. and Çatay B. (2007) 'Third-Party Logistics Provider Selection: Insights from a Turkish Automotive Company', Supply Chain Management: An International Journal, Vol. 12, No. 6, pp. 379-384.

Haas D. A., Murphy F. H. and Lancioni R. A. (2003) 'Managing Reverse Logistics Channels with Data Envelopment Analysis', Transportation Journal, Vol. 42, No. 3, pp. 59-69.

Işıklar G., Alptekin E. and Büyüközkan G. (2007) 'Application of a Hybrid Intelligent Decision Support Model in Logistics Outsourcing', Computers \& Operations Research, Vol. 34, No. 12, pp. 3701-3714.

Kim S. H., Park C. G. and Park K. S. (1999) 'An Application of Data Envelopment Analysis in Telephone Offices Evaluation with Partial data', Computers \& Operations Research, Vol. 26, No. 1, pp. 59-72. 
Liu H. T. and Wang W. K. 'An Integrated Fuzzy Approach for Provider Evaluation and Selection in Third-Party Logistics', Expert Systems with Application, in press.

Meade L. and Sarkis J. (2002) 'A Conceptual Model for Selecting and Evaluating ThirdParty Reverse Logistics Providers', Supply Chain Management: An International Journal, Vol. 7, No. 5, pp. 283-295.

Prahinski C. and Kocabasoglu C. (2006) 'Empirical Research Opportunities in Reverse Supply Chains’, Omega, Vol. 34, No. 6, pp. 519-532.

Qureshi M. N., Kumar D. and Kumar P. (2008) 'Decision support model for evaluation and selection of Third Party Logistics service providers', International Journal of Logistics Systems and Management, Vol. 4, No.3, pp. 255-281.

Zhu J. (2003) 'Imprecise Data Envelopment Analysis (IDEA): A Review and Improvement with an Application', European Journal of Operational Research, Vol. 144, No. 3, pp. 513-529. 
Table 1. Related attributes for eighteen 3PL providers and efficiency scores

\begin{tabular}{|c|c|c|c|c|}
\hline \multirow{2}{*}{$\begin{array}{c}\text { 3PL provider } \\
\text { No. } \\
\text { (DMU) }\end{array}$} & \multicolumn{2}{|c|}{ Inputs } & \multirow{2}{*}{$\begin{array}{c}\text { Output } \\
\text { NB } \\
y_{1 j}\end{array}$} & \multirow[b]{2}{*}{ Efficiency } \\
\hline & $\begin{array}{l}\text { TC } \\
x_{1 j}\end{array}$ & $\begin{array}{l}3 \mathrm{R}^{*} \\
x_{2 j}\end{array}$ & & \\
\hline 1 & 253 & 5 & {$[50,65]$} & .722 \\
\hline 2 & 268 & 10 & {$[60,70]$} & .7 \\
\hline 3 & 259 & 3 & {$[40,50]$} & .556 \\
\hline 4 & 180 & 6 & {$[100,160]$} & 1 \\
\hline 5 & 257 & 4 & {$[45,55]$} & .611 \\
\hline 6 & 248 & 2 & {$[85,115]$} & 1 \\
\hline 7 & 272 & 8 & {$[70,95]$} & .95 \\
\hline 8 & 330 & 11 & {$[100,180]$} & 1 \\
\hline 9 & 327 & 9 & {$[90,120]$} & 1 \\
\hline 10 & 330 & 7 & {$[50,80]$} & .8 \\
\hline 11 & 321 & 16 & {$[250,300]$} & 1 \\
\hline 12 & 329 & 14 & {$[100,150]$} & .75 \\
\hline 13 & 281 & 15 & {$[80,120]$} & .66 \\
\hline 14 & 309 & 13 & {$[200,350]$} & 1 \\
\hline 15 & 291 & 12 & {$[40,55]$} & .55 \\
\hline 16 & 334 & 17 & {$[75,85]$} & .34 \\
\hline 17 & 249 & 1 & {$[90,180]$} & 1 \\
\hline 18 & 216 & 18 & {$[90,150]$} & .892 \\
\hline
\end{tabular}

${ }^{1}$ A local optimum of a problem is a solution optimal within a neighboring set of solutions. This is in contrast to a global optimum, which is the optimal solution among all possible solutions. 